\title{
Radon-based technique for the analysis of atmospheric stability - a case study from Central Poland
}

Agnieszka Podstawczyńska, Scott D. Chambers

\begin{abstract}
An economical and easy-to-implement technique is outlined by which the mean nocturnal atmospheric mixing state ("stability") can be assessed over a broad (city-scale) heterogeneous region solely based on near-surface ( $2 \mathrm{~m}$ above ground level [a.g.l.]) observations of the passive tracer radon-222. The results presented here are mainly based on summer data of hourly meteorological and radon observations near Łodź, Central Poland, from 4 years (2008-2011). Behaviour of the near-surface wind speed and vertical temperature gradient (the primary controls of the nocturnal atmospheric mixing state), as well as the urban heat island intensity, are investigated within each of the four radon-based nocturnal stability categories derived for this study (least stable, weakly stable, moderately stable, and stable). On average, the most (least) stable nights were characterized by vertical temperature gradient of $1.1(0.5)^{\circ} \mathrm{C} \cdot \mathrm{m}^{-1}$, wind speed of $\sim 0.4(\sim 1.0) \mathrm{m} \cdot \mathrm{s}^{-1}$, and urban heat island intensity of $4.5(0.5)^{\circ} \mathrm{C}$. For sites more than $20 \mathrm{~km}$ inland from the coast, where soils are not completely saturated or frozen, radon-based nocturnal stability classification can significantly enhance and simplify a range of environmental research applications (e.g. urban climate studies, urban pollution studies, regulatory dispersion modelling, and evaluating the performance of regional climate and pollution models).
\end{abstract}

Keywords: radon-222 • Central Poland • stability classification • stable nocturnal boundary layer • atmospheric mixing state

\author{
A. Podstawczyńska \\ Department of Meteorology and Climatology \\ Faculty of Geographical Sciences \\ University of Lodz \\ 88 Narutowicza St., 90-139 Łódź, Poland \\ E-mail: apodstaw@uni.lodz.pl \\ S. D. Chambers
}

ANSTO Institute for Environmental Research

Locked Bag 2001, Kirrawee DC, NSW 2232, Australia

Received: 5 February 2018

Accepted: 25 May 2018

\section{Introduction}

The ability of the atmosphere to disperse excess heat or pollutants within an urban canopy depends on the atmospheric mixing state ("stability"). Traditional (meteorological) stability measures seek to quantify the combined influences of mechanical mixing and thermodynamic stability through near-surface observations of wind speed and temperature or their vertical gradients. Such methods are either categorical (and thus approximate, e.g. Pasquill-Gifford typing [1,2]) or subject to unrealistic ideal fetch requirements or expensive or labour intensive to implement over broad regions (e.g. Richardson number, Monin-Obukhov similarity theory [3]). Recent studies [3-8] have demonstrated that a relative classification for the combined influences of all near-surface atmospheric mixing processes at night can be effectively determined solely through near-surface observations of atmospheric radon-222 (radon) concentrations.

The poorly soluble, noble gas radon is the gaseous decay product of uranium-238, ubiquitous in all rocks and soils. The terrestrial surface (unfrozen and unsaturated) is the only significant source of radon, over which its emission has historically been considered as relatively well constrained and well 
distributed (terrestrial radon flux of $0.75-1.25$ atoms per $\mathrm{cm}^{2} \cdot$ s excluding polar regions [9-13], however, suggests a greater variability). Although meteorological factors (e.g. wind speed, pressure, or rainfall) can locally alter the radon flux on hourly to daily timescales, the average emission over synoptic to seasonal timescales is more consistent than anthropogenic emissions. Unlike many atmospheric trace constituents, the short half-life of radon (3.8 days) prevents it from accumulating in the atmosphere on greater than synoptic timescales, although this period is long enough compared to mixing timescales within the boundary layer for radon to be considered as a relatively conservative tracer for either daytime or nocturnal mixing studies. The combined physical characteristics of radon make it a powerful, unambiguous indicator of the integrated effects of all near-surface vertical mixing processes [3, 4, 8, 14].

A qualitative relationship between near-surface radon concentrations and atmospheric mixing (or stability) has been realized and exploited by numerous researchers over the past century [15-25]. Until recently, however, more quantitative relationships have remained elusive due to a lack of separate attention being paid to the three main contributing factors to observed radon concentrations: (i) dilution of relatively consistent local surface emissions within a diurnally changing mixing depth; (ii) advection or fetch effects due to the 2-week atmospheric "memory" imposed by radon's half-life, and (iii) short-term (meteorologically induced) variability in the local radon flux. Only the first of these contributions is directly and uniquely related to the atmospheric mixing state. For absolute radon concentrations at a particular site to be related in a consistent quantitative way to the nocturnal mixing state, first, fetch effects need to be removed from the radon observations and second, subsequent statistics need to be generated from averages over synoptic to seasonal timescales to account for short-term local radon flux variability.

The most reliable way to account for fetch effects is to measure vertical radon gradients [3, 14], but running multiple research-grade detectors can be costly. Some researchers have sought to avoid fetch contributions by limiting their studies to short periods of near-stationary atmospheric behaviour [26], but this necessitates rejecting large amounts of data. Others have made use of the fact that observing time rates of change in radon concentration mostly accounts for fetch effects [27-29]. Chambers et al. [4] proposed a simple technique based on measurements at only a single height that approximately separated fetch and mixing contributions of long-term atmospheric radon observations and showed for the first time how to relate the mixing component of this signal to the mean nocturnal mixing state at a given site. Recently, Podstawczyńska [7] and Chambers et al. [5] applied this technique for the first time to urban climate studies.

The aims of this study were to provide (i) a step-by-step explanation of exactly how the technique can be applied based on a case study dataset from Central Poland and (ii) a summary of potential applications so far conceived for this kind of analysis, including references to existing studies.

\section{Sites and equipment}

This study is based predominantly on summer observations of paired hourly meteorological and atmospheric radon within and outside the urban region of Łódź, Central Poland, from 4 years (January 2008 to December 2011) (Fig. 1). The urban and rural sites were separated by a distance of approximately $25 \mathrm{~km}$. Detailed descriptions of the measurement sites, instrumentation, and data quality control

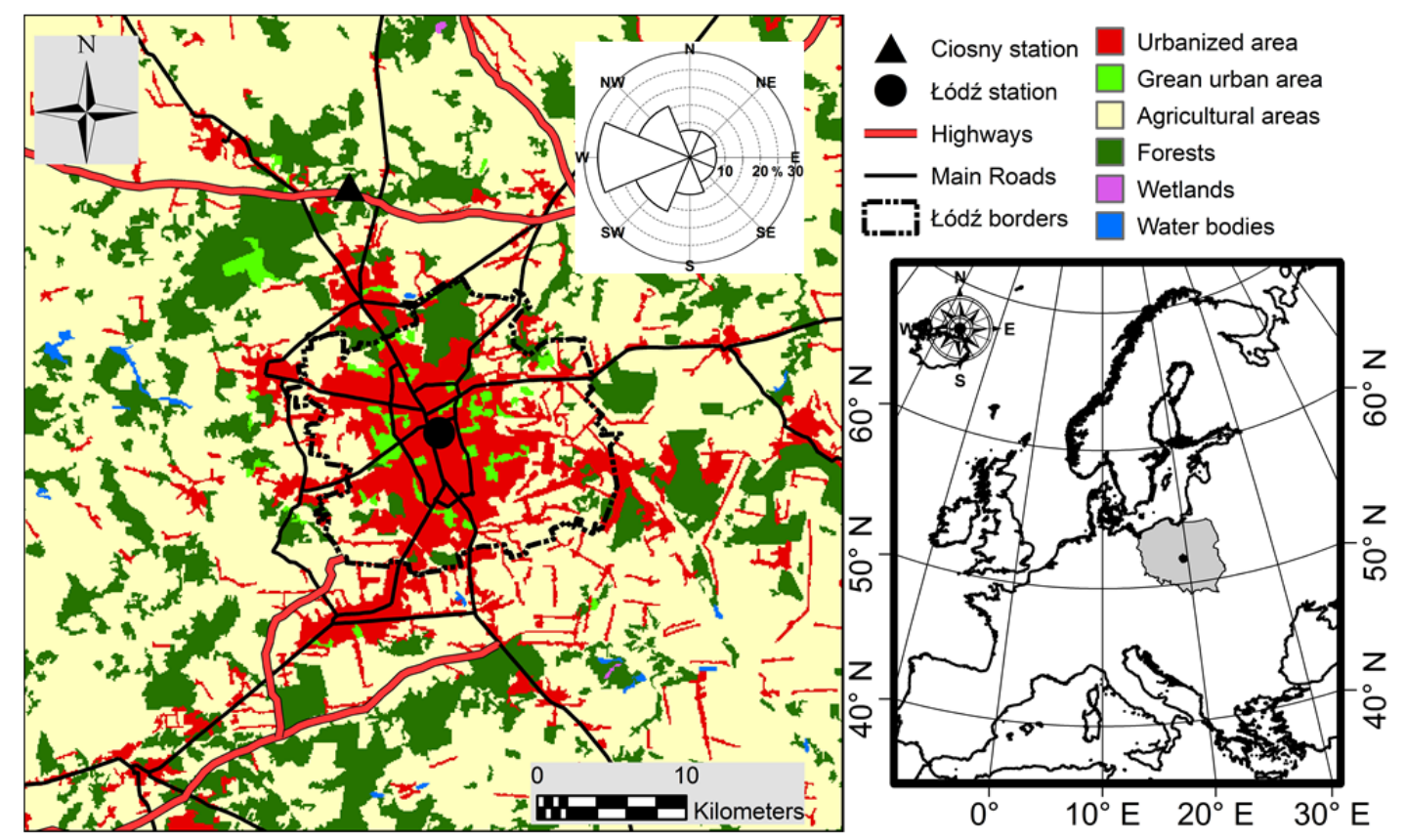

Fig. 1. Relative location of study sites with respect to the city of Łódź, relative location of Łódź within Europe, and wind rose indicating the percentage of fetch directions for the 2008-2011 period. 
have already been provided by Podstawczyńska [7] and Chambers et al. [5]. Briefly, wind speed, direction, temperature, relative humidity and pressure were measured from 10 and $2 \mathrm{~m}$ towers in the urban and rural sites, respectively. Vertical air temperature gradients between 0.2 and $2 \mathrm{~m}$ a.g.l. were measured at both sites. Atmospheric radon concentration was measured at $2 \mathrm{~m}$ a.g.l. at both sites using commercial AlphaGUARD (PQ 2000 PRO, Genitron Instruments) ionization chambers operating in the diffusion mode with a 1-h integration time, mounted in Stevenson Screen shelters. Intercomparisons of the $\mathrm{Rn}-222$ and meteorological monitoring equipment for both stations were performed before and during measurement campaign. All meteorological observations were integrated to hourly values for analysis and were checked in detail for consistency. All reported times were local times $(\mathrm{LST}=\mathrm{UTC}+1 \mathrm{~h})$.

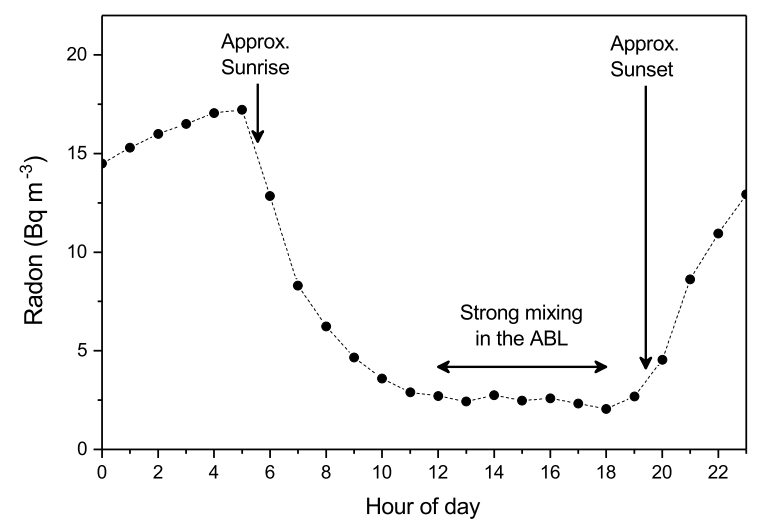

Fig. 2. Diurnal composite mean-hourly radon concentrations at Ciosny (rural site) under "fair weather" conditions in summer 2008.

\section{Methods}

A typical diurnal cycle of radon in summer is shown in Fig. 2. The cycle is characterized by a pre-dawn maximum, when the nocturnal boundary layer (NBL) is typically shallowest and most stable, and an afternoon minimum, when the atmospheric boundary layer (ABL) is deepest and most well mixed. A rapid decrease is observed between sunrise and noon as the nocturnal inversion is eroded by convective turbulence, and the high surface concentrations are mixed into the residual layer (RL) from the previous day. Concentrations begin to increase again shortly before sunset as the nocturnal inversion begins to form again from the ground up and gradually strengthen.

For a given site and season, the amplitude of the diurnal cycle is primarily controlled by (i) the depth of the NBL (since the radon source function is relatively consistent and well distributed over the typical scales of nocturnal fetch) and (ii) the radon sampling height a.g.l. [30]. The afternoon minimum concentration, on the other hand, upon which the diurnal amplitude is superimposed, is controlled by (i) the air mass' fetch history (the strength of the various radon sources passed over in the past 2 weeks), (ii) the depth of the ABL, and (iii) venting (entrainment) that has occurred from (to) the ABL [30-32].

Figure 3a shows 10 days of hourly radon observations where diurnal variability and changing afternoon minimum values are evident. As discussed in Chambers et al. [5], at this site, afternoon radon concentrations $>1.5 \mathrm{~Bq} \cdot \mathrm{m}^{-3}$ (e.g. on day 137) were typically associated with easterly or westerly fetch

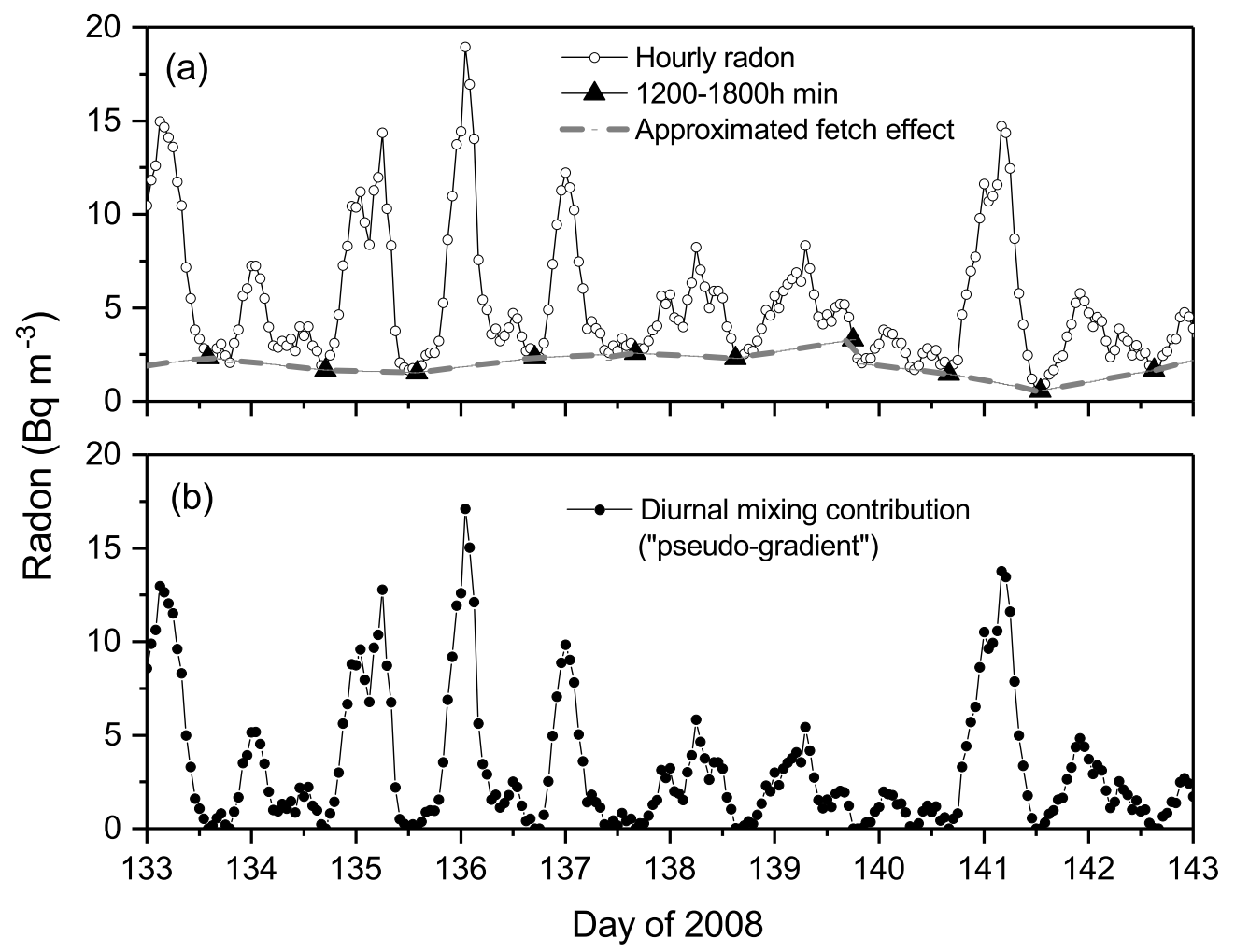

Fig. 3. Hourly mean (a) observed radon, afternoon minimum values, and interpolated estimation of fetch influences and (b) diurnal mixing component of radon time series $\left(R n_{\text {observed }}-R_{n_{\text {fetch }}}\right)$. 
or slow-moving air masses (i.e. a long recent air mass time-over-land). By contrast, afternoon radon concentrations $<1.5 \mathrm{~Bq} \cdot \mathrm{m}^{-3}$ (e.g. day 141) were typically associated with faster moving air masses or fetch from the northwest (recently from the ocean, from which the radon flux is essentially zero). These greater-than-diurnal timescale changes in absolute radon concentration $\left(\sim 3 \mathrm{~Bq} \cdot \mathrm{m}^{-3}\right.$ at this site $)$ are not related to local changes in atmospheric mixing (i.e. stability).

At night, when the stable NBL forms, radon gradually increases above the afternoon minimum value. Above the NBL (in the RL), however, radon concentrations typically remain around the previous afternoon minimum value. In the afternoon, when the ABL is deep and well mixed, there is usually very little difference between the $2 \mathrm{~m}$ radon concentration and the radon concentration observed much higher in the ABL $[16,31]$. It is therefore possible to approximate a radon measurement at a second height (above the extent of the nocturnal inversion) by linearly interpolating between afternoon minimum values of the $2 \mathrm{~m}$ observations (e.g. dashed line in Fig. 3a). Fetch effects on the observed $2 \mathrm{~m}$ radon time series can then be approximately accounted for by calculating the vertical gradient between the observed and fabricated (interpolated) radon time series. We refer to this as a "pseudo-gradient", and it represents the diurnally varying mixing-related contribution to the observed radon time series (Fig. 3b).

The solid triangles in Fig. 3a represent the minimum radon concentration each day between 1200 and $1800 \mathrm{~h}$. Minimum values occurring outside this 6-hour afternoon window are likely to be due to changes in air mass fetch, not changing mixing depth. The fetch contribution to the $2 \mathrm{~m}$ radon time series is approximated for a complete dataset simply by linearly interpolating between afternoon minimum values. In cases when the interpolated series would result in some negative pseudo-gradient values (e.g. between days 139 and 140; Fig. 3a), the interpolation routine moves to the next hourly observed value and attempts once more to interpolate to the next afternoon minimum value. The end result is the minimum number of straight line segments joining successive afternoon minimum values such that the pseudo-gradient is never negative.

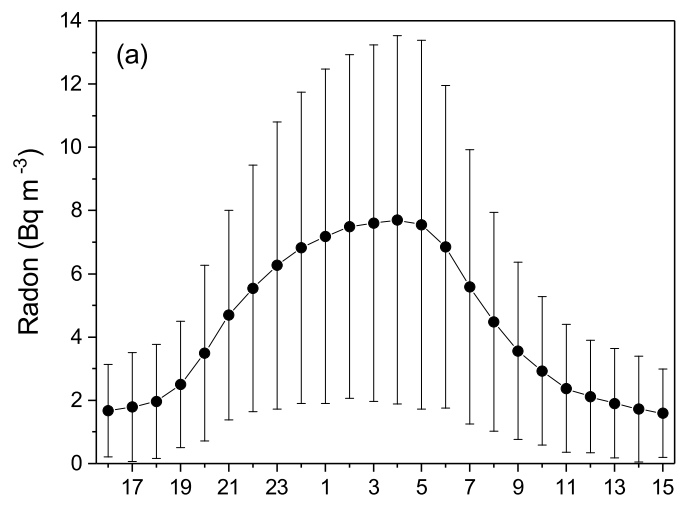

A diurnal composite of the radon pseudo-gradient for all non-precipitating summer days in 2008-2011 is shown in Fig. 4a (note that the lower limit of detection of the AlphaGUARD detectors is approximately $2 \mathrm{~Bq} \cdot \mathrm{m}^{-3}$ ). For the purpose of radon-based atmospheric stability analysis, we have defined 24-hour periods of data from afternoon to afternoon (1500-1400 h), between times of minimum radon concentration, rather than from midnight to midnight. The larger standard deviation of radon at night in Fig. 4a compared to that during the afternoon is evidence that relative changes in the typical nocturnal mixing depth are much larger than relative changes in the typical ABL depth. The corollary being that within a given season, fetch effects dominate radon variability in the afternoons and changes in mixing depth dominate nocturnal radon variability.

For the entire multi-year dataset, we now define a 10-hour nocturnal window from sunset to sunrise of the shortest night in the year (Fig. 4b). Since fetch effects have been removed, the average pseudo-gradient value over this nocturnal window will be directly related to the average of all combined nocturnal near-surface atmospheric mixing processes. If analysing data from multiple seasons, in order to account for the effects of seasonality (changing day length), as described in Chambers et al. [6] and Williams et al. [8], it is necessary to subtract the initial value of this window period $\left([\mathrm{Rn}]_{1900 \mathrm{~h}}\right)$ each night from the mean pseudo-gradient within the 10-hour nocturnal window. A cumulative frequency plot of nocturnal mean summertime pseudo-gradient values (referenced to the $1900 \mathrm{~h}$ value) is shown in Fig. 5a. Note that, in order to simplify the appearance of Fig. 5a to facilitate this discussion, a small positive shift was applied to the radon bin values to account for times when referencing to the $1900 \mathrm{~h}$ value resulted in negative mean pseudo-gradient values (e.g. during the passage of strong frontal systems involving large sudden fetch changes).

Radon concentrations corresponding to quartile ranges of the nocturnal pseudo-gradient values were then used as thresholds to distinguish between different nocturnal atmospheric mixing states (Fig. 5a; note that threshold values will be site specific due to changes in the local radon flux). At sites when

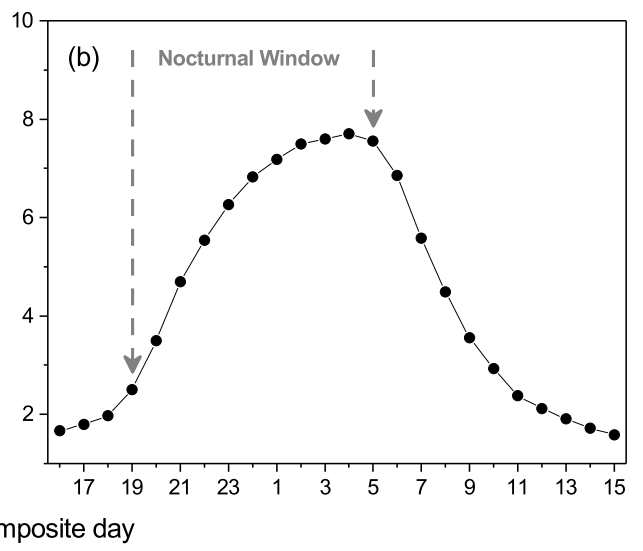

Fig. 4. (a) Diurnal composite radon pseudo-gradient at the rural site under non-precipitating conditions in the summers of 2008-2011 (time axis shifted to emphasise nocturnal period) and (b) depiction of the 10-hour nocturnal window. Whiskers represent $\pm 1 \sigma$. 

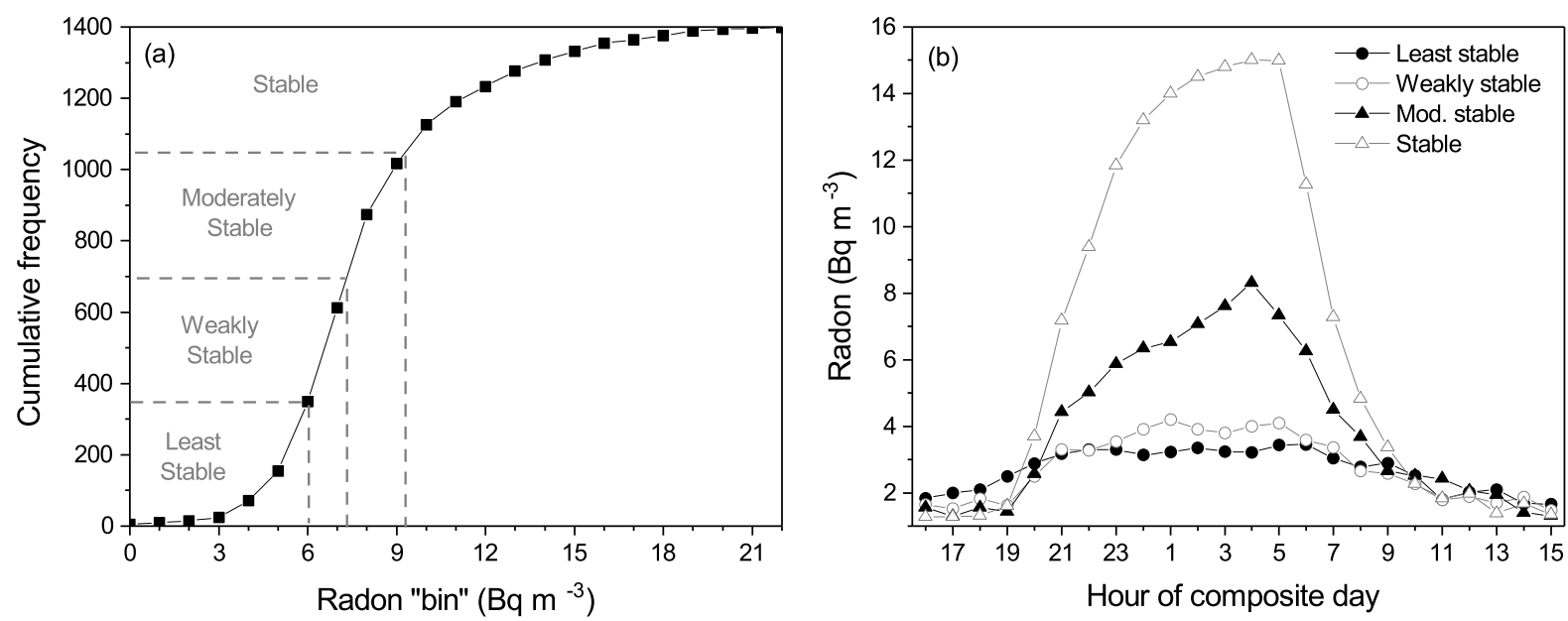

Fig. 5. (a) Cumulative frequency diagram of nocturnal mean summer radon pseudo-gradient over the 10-hour nocturnal window and (b) diurnal composite plots of the radon pseudo-gradient in summer according to each of the defined nocturnal mixing categories.

significant snow cover or soil saturation is common at some times of the year (potentially changing the local radon flux for extended periods), this classification of mixing states should be performed separately for each season [6, 8]. Each 24-hour period $(1500-1400 \mathrm{~h})$ of the entire dataset is then assigned a label according to the nocturnal mixing category (e.g. 1 = least stable, 2 = weakly stable, $3=$ moderately stable, and $4=$ stable). As an example of how these categories are subsequently used, diurnal composites of the radon pseudo-gradient within each mixing category in summer are presented in Fig. 5b.

At this site, when the least stable nocturnal conditions prevailed, the amplitude of the diurnal cycle of the radon pseudo-gradient was small $\left(<2 \mathrm{~Bq} \cdot \mathrm{m}^{-3}\right.$; Fig. 5b). Conversely, when stable nocturnal conditions prevailed, the corresponding amplitude was greater than a factor of 10. Although the radon threshold values defining nocturnal mixing states in Fig. 5a are site and season specific, the approach used here to define nocturnal stability states in summer can be universally applied to most sites (except within $20 \mathrm{~km}$ of the coast, where strong spatial gradients in the radon source function exist, or high-elevation sites where anabatic/katabatic flows are common).
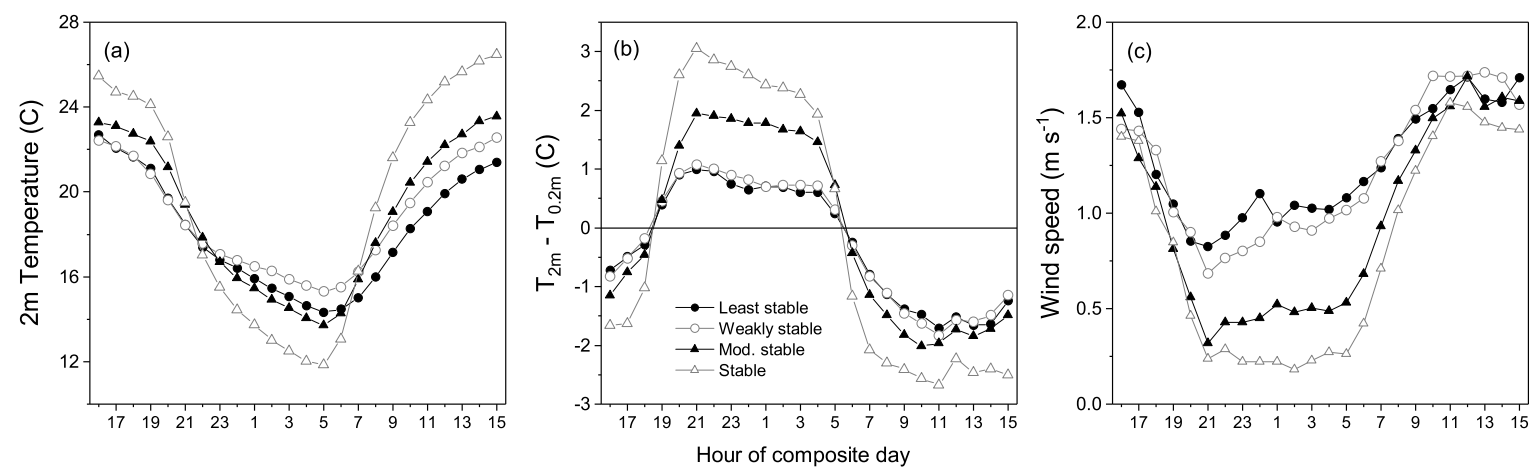

Fig. 6. Summer diurnal composites of (a) $2 \mathrm{~m}$ air temperature, (b) near-surface vertical temperature gradient, and (c) wind speed at the rural site as a function of nocturnal stability category for the 2008-2011 period.
To demonstrate how the above classification scheme for the nocturnal mixing state can be applied to companion datasets, diurnal composite plots of $2 \mathrm{~m}$ air temperature, $2-0.2 \mathrm{~m}$ vertical temperature gradient, and wind speed at the rural site for the summer months of 2008-2011 are shown in Fig. 6.

In all, 24-hour periods classified as having the most stable nocturnal conditions had the largest amplitude diurnal temperature cycle (Fig. 6a), largest near-surface vertical temperature gradients (Fig. 6b), and lowest nocturnal wind speeds (Fig. 6c). Conversely, least stable nocturnal conditions were associated with low amplitude diurnal temperature cycles and higher nocturnal wind speeds.

Often, the meteorological conditions giving rise to stable nights (clear skies and low-gradient winds) the hot daytime temperatures and strong daytime near-surface vertical temperature gradients following a stable night. Similarly, windy and cloudy conditions giving rise to the least stable nocturnal conditions persist through to the following day, resulting in lower daytime temperatures and smaller near-surface vertical temperature gradients following a "least stable" night. A corollary of this observation is that nocturnal radon-based atmospheric stability classification can also provide useful (approximate) persist through to the following day, as evidenced by 


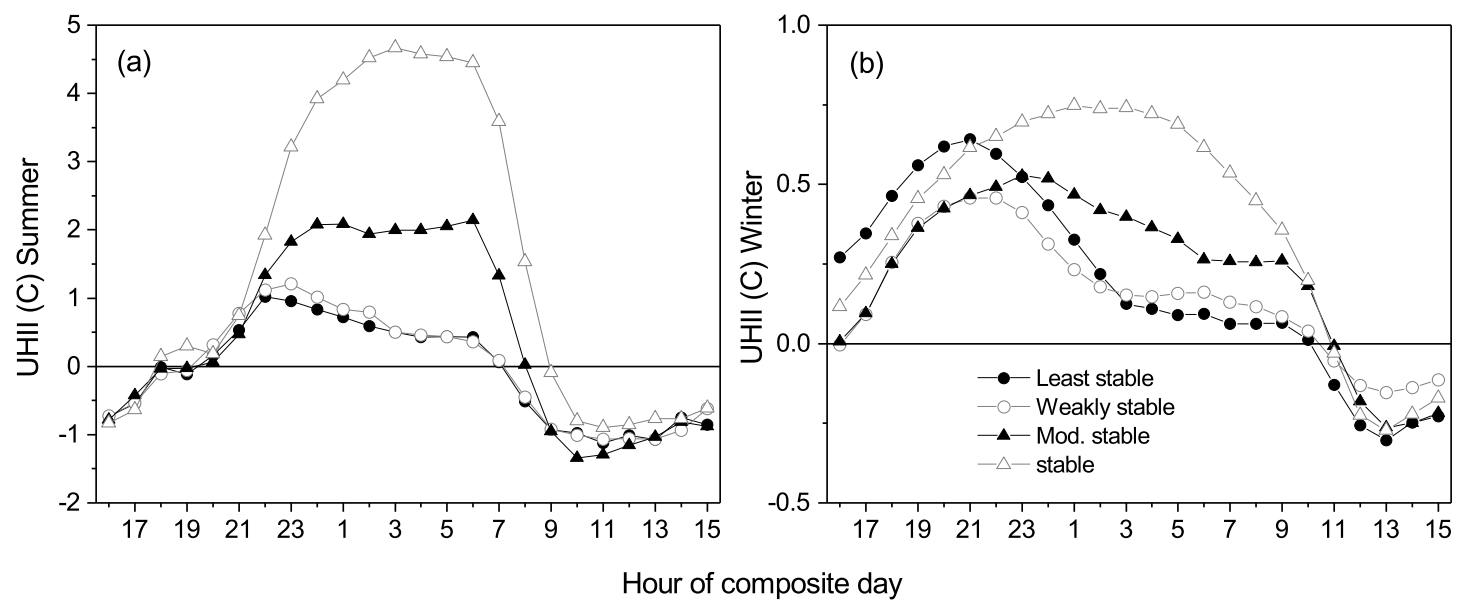

Fig. 7. Diurnal composites of the urban heat island intensity (UHII) in (a) summer and (b) winter, as a function of radon-derived nocturnal atmospheric stability category for the 2008-2011 period.

information regarding adjacent daytime conditions due to short-term atmospheric persistence.

Since the afternoon (1200-1800 h) variability of radon is small (e.g. Fig. 2) and is dominated by changing fetch conditions, these observations cannot be used directly to infer the daytime mixing state. However, by investigating the rates of change in radon concentration in either side of the afternoon window (e.g. 500-800 h and 1900-2300 h) and considering the distribution of these gradients for the whole dataset as shown for nocturnal radon concentrations in Fig. 5a, radon observations can also be used to directly infer the daytime atmospheric mixing state. Refinement of this approach, which is based on early investigations by Perrino et al. [28, 29], is a subject of ongoing research.

Figure 7 shows diurnal composite plots of the urban heat island intensity (UHII) $\left(T_{2 \mathrm{~m} \_ \text {_rban }}-T_{2 \mathrm{~m}_{\text {_rural }}}\right)$ in summer and winter as a function of radon-derived stability category. The consistency of the results demonstrates that while the radon-based stability classification was derived only at the rural site, it also applies equally well at the urban site, some $25 \mathrm{~km}$ away. This is not to say that the same absolute atmospheric stability simultaneously exists over the rural and urban regions; rather, in a relative sense, conditions will change from least stable to most stable on the same nights over the rural and urban regions. A corollary of this observation is that radon-derived atmospheric stability classification based on a single observation can be applied across a region larger than a typical urban centre.

In both summer and winter, stable nights (clear sky, low wind speed conditions) gave rise to the largest UHII values. In winter, however, with frequent snow cover, maximum UHII values were approximately a factor of 6 lower than those in summer (see also [5]). Under "least stable" nocturnal conditions (cloudy and windy), UHII values were lower than their maximum by more than a factor of 7 .

In addition to the utility of the radon-based stability classification method for urban climate studies demonstrated here and in Podstawczyńska [7] and Chambers et al. [5], there are numerous other applications. This relatively new technique has already been effectively used in several urban pollution studies $[4,8,33]$. By selectively targeting stable nocturnal conditions and using near-surface radon observations to account for dilution of emissions within the ABL, Williams et al. [8] were able to relate observed concentrations of benzene and carbon monoxide to traffic density in the city of Bern, Switzerland, with unprecedented accuracy. Furthermore, Chambers et al. [6] used this technique in the vicinity of a decommissioned nuclear research reactor near Bucharest, Romania, to investigate the influence of atmospheric stability on tritium releases and what impact this may have on neighbouring agricultural regions. A conclusion of this study was that radon-based atmospheric stability classification has the potential to significantly enhance routine dispersion modelling efforts in the vicinity of research and power reactors since the results are demonstrably superior to those obtained using more conventional Pasquill-Gifford stability typing. Williams et al. [3] demonstrated that measurements of the near-surface accumulation of radon can provide more detailed information about the nocturnal atmospheric mixing state than conventional micrometeorological techniques (e.g. Richardson number or Monin-Obukhov similarity theory). Lastly, Pal et al. [30] used the radon-based stability analysis technique to improve understanding of the daytime behaviour of trace gases in the ABL.

\section{Conclusions}

Single-height, near-surface radon measurements are capable of providing classification of the atmospheric mixing state more consistently, accurately, and economically than conventional meteorological techniques. Furthermore, the radon-based stability classification approach is completely independent of meteorological observations and is not subject to ideal fetch requirements. Since the technique is applied at night, when radon concentrations are the highest, instrumental lower limit of detection and absolute accuracy requirements are also comparatively relaxed, making it possible to use portable, 
relatively inexpensive commercial analysers. Furthermore, stability classification determined from a single measurement site can be applied without significant loss of generality across spatial regions the size of a large urban centre. This approach therefore brings effective and consistent atmospheric stability classification well within reach of projects with limited resources, potentially increasing the number of monitoring stations for other related parameters that could be established on a set budget.

Acknowledgment. The authors wish to thank the Laboratory of Radiometric Expertise team at the Institute of Nuclear Physics, Polish Academy of Sciences, Kraków, for help with the measurement of Rn-222 concentrations. The authors also wish to thank the teams at the Department of Hydrology and Water Management and the Department of Meteorology and Climatology, Faculty of Geographical Sciences, University of Łodź, for their help with the measurement campaign. Funding for this research was partially provided by the Polish Ministry of Science and Higher Education under grants N306 015 32/1011 and N306 276935 in the years 2007-2011.

\section{References}

1. Pasquil, D. (1961). The estimation of the dispersion of windborne material. Met. Mag., 90, 33-49.

2. Turner, B. (1964). A diffusion model for an urban area. J. Appl. Meteorol., 3, 83-91.

3. Williams, A. G., Chambers, S. D., \& Griffiths, A. (2013). Bulk mixing and decoupling of the nocturnal stable boundary layer characterized using a ubiquitous natural tracer. Bound.-Layer Meteor., 149, 381-402. doi: 10.1007/s10546-013-9849-3.

4. Chambers, S. D., Williams, A. G., Crawford, J., \& Griffiths, A. D. (2015). On the use of radon for quantifying the effects of atmospheric stability on urban emissions. Atmos. Chem. Phys., 15, 1175-1190.

5. Chambers, S. D., Podstawczyńska, A., Williams, A. G., \& Pawlak, W. (2016a). Characterising the influence of atmospheric mixing state on urban heat Island intensity using radon-222. Atmos. Environ., 147, 355-368.

6. Chambers, S. D., Galeriu, D., Williams, A. G., Melintescu, A., Griffiths, A. D., Crawford, J., Dyer, L., Duma, M., \& Zorila, B. (2016b). Atmospheric stability effects on potential radiological releases at a nuclear research facility in Romania: characterising the atmospheric mixing state. J. Environ. Radioact., 154, 68-82.

7. Podstawczyńska, A. (2016). Differences of nearground atmospheric Rn-222 concentration between urban and rural area with reference to microclimate diversity. Atmos. Environ., 126, 225-234.

8. Williams, A. G., Chambers, S. D., Conen, F., Reimann, S., Hill, M., Griffiths, A. D., \& Crawford, J. (2016). Radon as a tracer of atmospheric influences on trafficrelated air pollution in a small inland city. Tellus Ser. B-Chem. Phys. Meteorol., 68, 30967. DOI: 10.3402/ tellusb.v68.30967.

9. Turekian, K. K., Nozaki, Y., \& Benninger, L. K. (1977). Geochemistry of atmospheric radon and radon products. Annu. Rev. Earth Planet. Sci., 5, 227-255.

10. Balkanski, Y. J., Jacob, D. J., Gardner, G. M., Graustein, W. M., \& Turekian, K. K. (1993). Transport and residence times of continental aerosols inferred from a global three-dimensional simulation of ${ }^{210} \mathrm{~Pb}$. J. Geophys. Res.-Atmos., 98(D11), 20573-20586. DOI: 10.1029/93JD02456.

11. Szegvary, T., Conen, F., \& Ciais, P. (2009). European 222Rn inventory for applied atmospheric studies. Atmos. Environ., 43(8), 1536-1539.

12. Griffiths, A. D., Zahorowski, W., Element, A., \& Werczynski, S. (2010). A map of radon flux at the Australian land surface. Atmos. Chem. Phys., 10, 8969-8982.

13. Karstens, U., Schwingshackl, C., Schmithusen, D., \& Levin, I. (2015). A process-based ${ }^{222}$ radon flux map for Europe and its comparison to long-term observations. Atmos. Chem. Phys., 15, 12845-12865. DOI: 10.5194/acp-15-12845-2015.

14. Chambers, S. D., Williams, A. G., Zahorowski, W., Griffiths, A., \& Crawford, J. (2011). Separating remote fetch and local mixing influences on vertical radon measurements in the lower atmosphere. Tellus Ser. B-Chem. Phys. Meteorol., 63, 843-859. DOI: 10.1111/j.1600-0889.2011.00565.x.

15. Wigand, A., \& Wenk, F. (1928). Der gehalt der luftan radium-emanation, nach Messungenbei Flugzeugaufstiegen. Ann. Phys., 86(13), 657-686.

16. Moses, H., Stehney, A. F., \& Lucas, H. F. J. (1960). The effect of meteorological variables upon the vertical and temporal distributions of atmospheric radon. J. Geophys. Res., 65, 1223-1238.

17. Sisigina, T. I. (1964). Vertical distribution of radon in the boundary layer of the atmosphere $(0-300 \mathrm{~m})$ in connection with changing meteorological conditions. U.D.C.551.594.1. Izv. Geophys., 3, 414-421.

18. Hosler, C. R. (1966). Meteorological effects on atmospheric concentrations of radon (Rn222), RaB (Pb214), and $\mathrm{RaC}(\mathrm{Bi} 214)$ near the ground. Mon. Weather Rev., 94, 89.

19. Allegrini, I., Febo, A., Pasini, A., \& Schiarini, S. (1994). Monitoring of the nocturnal mixed layer by means of participate radon progeny measurement. J. Geophys. Res.-Atmos., 99, 18765-18777. DOI: 10.1029/94JD00783.

20. Desideri, D., Roselli, C., Feduzi, L., \& Meli, M. A. (2006). Monitoring the atmospheric stability by using radon concentration measurements: a study in a central Italy site. J. Radioanal. Nucl. Chem., 270, 523-530.

21. Vecchi, R., Marcazzan, G., \& Valli, G. (2007). A study on nighttime-daytime PM10 concentration and elemental composition in relation to atmospheric dispersion in the urban area of Milan (Italy). Atmos. Environ., 41, 2136-2144.

22. Wang, F., Zhang, H., Ancora, M. P., \& Deng, X. -D. (2013). Measurement of atmospheric stability index by monitoring radon natural radioactivity. China Environ. Sci., 33(4), 594-598.

23. Avino, P., Brocco, D., Lepore, L., \& Pareti, S. (2003). Interpretation of atmospheric pollution phenomena in relationship with the vertical atmospheric remixing by means of natural radioactivity measurements (radon) of particulate matter. Ann. Chim., 93(5/6), 589-594. 
24. Pitari, G., De Luca, N., Coppari, E., Di Carlo, P., \& Di Genova, G. (2015). Seasonal variation of night-time accumulated Rn-222 in central Italy. Environ. Earth Sci., 73(12), 8589-8597. DOI: 10.1007/s12665-015-4023-5.

25. Bulko, M., Holy, K., \& Mullerova, M. (2018). On the relation between outdoor ${ }^{222} \mathrm{Rn}$ and atmospheric stability determined by a modified Turner method. J. Environ. Radioact., 189, 79-92.

26. Cohen, L. D., Barr., S., Krablin, R., \& Newstein, H. (1972). Steady-state vertical turbulent diffusion of radon. J. Geophys. Res., 77, 2654-2668.

27. Fujinami, N., \& Osaka, S. (1987). Variations in radon 222 daughter concentrations in surface air with atmospheric stability. J. Geopys. Res.-Atmos., 92(d1), 1041-1043.

28. Perrino, C., Pietrodangelo, A., \& Febo, A. (2001). An atmospheric stability index based on radon progeny measurements for the evaluation of primary urban pollution. Atmos. Environ., 35, 5235-5244.

29. Perrino, C. (2012). Natural radioactivity from radon progeny as a tool for the interpretation of atmospheric pollution events. In Sources and measurements of radon and radon progeny applied to climate and air quality studies (pp. 151-159). Vienna: International Atomic Energy Agency. (IAEA Proceedings Series).

30. Pal, S., Lopez, M., Schmidt, M., Ramonet, M., Gibert, F., Xueref-Remy, I., \& Ciais, P. (2015). Investigation of the atmospheric boundary layer depth variability and its impact on the ${ }^{222} \mathrm{Rn}$ concentration at a rural site in France. J. Geophys. Res.-Atmos., 120, 623-643. DOI: 10.1002/2014JD022322.

31. Williams, A. G., Zahorowski, W., Chambers, S. D., Griffiths, A., Hacker, J. M., Element, A., \& Werczynski, S. (2011). The vertical distribution of radon in clear and cloudy daytime terrestrial boundary layers. J. Atmos. Sci., 68, 155-174. DOI: 10.1175/2012JAS3576.1.

32. Pal, S. (2014). Monitoring depth of shallow atmospheric boundary layer to complement LiDAR measurements affected by partial overlap. Remote Sens., 6(9), 8468-8493.

33. Wang, F., Chambers, S. D., Zhang, Z., Williams, A. G., Deng, X., Zhang, H., Lonati, G., Crawford, J., Griffiths, A. D., Ianniello, A., \& Allegrini, I. (2016). Quantifying stability influences on air pollution in Lanzhou, China, using a radon-based "stability monitor": seasonality and extreme events. Atmos. Environ., 145, 376-391. 